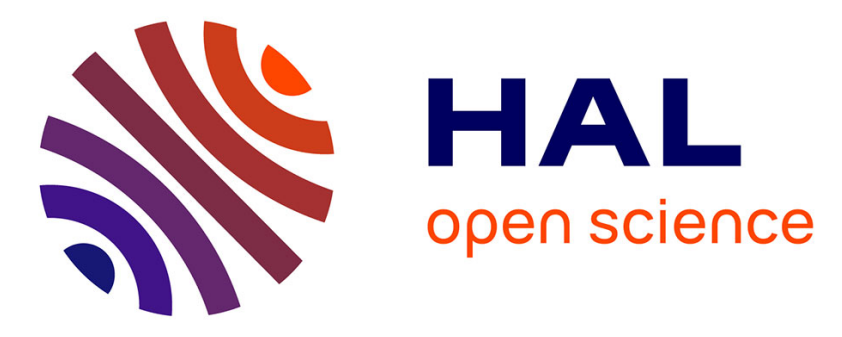

\title{
Revisiting of LED pumped bulk laser: first demonstration of Nd:YVO4 LED pumped laser
}

Adrien Barbet, François Balembois, Amandine Paul, Jean-Philippe Blanchot, Anne-Lise Viotti, Jacques Sabater, Frédéric Druon, Patrick Georges

\section{To cite this version:}

Adrien Barbet, François Balembois, Amandine Paul, Jean-Philippe Blanchot, Anne-Lise Viotti, et al.. Revisiting of LED pumped bulk laser: first demonstration of Nd:YVO4 LED pumped laser. Optics Letters, 2014, 39 (23), pp.6731-6734. 10.1364/OL.39.006731 . hal-01096408

\section{HAL Id: hal-01096408 \\ https://hal-iogs.archives-ouvertes.fr/hal-01096408}

Submitted on 17 Dec 2014

HAL is a multi-disciplinary open access archive for the deposit and dissemination of scientific research documents, whether they are published or not. The documents may come from teaching and research institutions in France or abroad, or from public or private research centers.
L'archive ouverte pluridisciplinaire HAL, est destinée au dépôt et à la diffusion de documents scientifiques de niveau recherche, publiés ou non, émanant des établissements d'enseignement et de recherche français ou étrangers, des laboratoires publics ou privés. 


\title{
Revisiting of LED pumped bulk laser: first demonstration of $\mathrm{Nd}$ : $\mathrm{YVO}_{4}$ LED pumped laser
}

\author{
Adrien Barbet, ${ }^{1, *}$ François Balembois, ${ }^{1}$ Amandine Paul, ${ }^{2}$ Jean-Philippe Blanchot, ${ }^{2}$ Anne-Lise Viotti, ${ }^{2}$ \\ Jacques Sabater, ${ }^{2}$ Frédéric Druon, ${ }^{1}$ and Patrick Georges ${ }^{1}$ \\ ${ }^{1}$ Laboratoire Charles Fabry, UMR 8501, Institut d'Optique, CNRS, Université Paris-Sud, 2 Avenue Augustin Fresnel, 91127 \\ Palaiseau Cedex, France \\ ${ }^{2}$ Effilux, 7 Avenue de l'Atlantique, 91940 Les Ulis, France \\ *Corresponding author: adrien.barbet@institutoptique.fr
}

\begin{abstract}
We describe here what is, to the best of our knowledge, the first LED pumped Nd:YVO laser. Near-IR LED arrays with a wavelength centered close to $850 \mathrm{~nm}$ were used to pump transversely the crystal. By pulsing LEDs, with a duration of the order of the laser transition lifetime, we obtained sufficient pump intensities to reach the laser threshold. At a frequency of $250 \mathrm{~Hz}$, we obtained an output energy of $40 \mu \mathrm{J}$ at $1064 \mathrm{~nm}$ for an input pump energy of $7.4 \mathrm{~mJ}$, which corresponds to an optical efficiency of $0.5 \%$. Experimental results of small signal gain are compared with theoretical analysis. () 2014 Optical Society of America

OCIS Codes: (140.3530) Lasers, neodymium, (140.3580) Lasers, solid-state, (140.3460) Lasers, (140.3410) Laser resonators, (230.3670) Light-emitting diodes

http://dx.doi.org/10.1364/OL.39.006731
\end{abstract}

After the first demonstration of the flashlamp pumped ruby laser by Maiman [1], LED pumping was demonstrated for the first time in 1964 in Dy: $\mathrm{CaF}_{2}$ crystal [2]. In the 1970s, different works on neodymium lasers (such as Nd:YAG or Nd-pentaphosphate) were published with LED as the pump source [3-8]. Laser effect was also demonstrated with an LED pumped Yb:YAG crystal [9]. LED pumped solid-state lasers were generally cooled below room temperature to increase the emission cross section of the gain media, LEDs' efficiency, and hence the laser efficiency.

At the beginning of the 1980s, LED pumping was progressively forsaken with the emergence of laser diodes. Thanks to their high efficiency and brightness, they rapidly became the favorite way to pump solid-state lasers. However, driven by the lighting market, LED performance have been recently improved by order of magnitudes. Starting from intensity of 0.1 to $10 \mathrm{~W} / \mathrm{cm}^{2}$ at cryogenic temperatures in the $70 \mathrm{~s}$, it now reaches up to $100 \mathrm{~W} / \mathrm{cm}^{2}$ (in continuous wave at $1 \mathrm{~A}$ ) at room temperature with efficiencies greater than $200 \mathrm{~lm} / \mathrm{W}$ [10]. In parallel, LED prices experienced a dramatic drop because of a massive production. Moreover, contrary to laser diodes, LEDs are less sensitive to electrostatic discharges and have a lifetime 3 to 4 times higher than laser diodes.

Those improvements have triggered a new interest and LED pumping has started to be revisited since 2008 . Turnbull and co-workers [11,12] took the opportunities offered by high performance visible blue LED to pump polymer lasers. By pulsing LEDs during few tens of ns, they succeeded to inject up to $160 \mathrm{~A}$, leading to a LED optical intensity of $255 \mathrm{~W} / \mathrm{cm}^{2}$ at $450 \mathrm{~nm}$ and demonstrated a laser effect at $568 \mathrm{~nm}$ from a polymer distributed feedback laser. Htein et al. [13,14] used a white LED to exploit all absorption bands of erbium and neodymium doped fibers in the visible range. They obtained $12 \mathrm{~dB}$ (at $1550 \mathrm{~nm}$ ) and $6 \mathrm{~dB}$ (at $1400 \mathrm{~nm}$ ) of amplification gain. Liu et al. [15] demonstrated a laser effect from a semiconductor monolithically pumped by a LED which operates in a thermoelectrophotonic regime.

Surprisingly, LED pumping of bulk crystals as in the pioneer ages has not been revisited yet. Recently, a Korean team studied theoretically the pumping of five gain media (Nd:YAG, Nd:glass, Nd/Cr:YAG, Ti:sapphire and solid dye) by two types of LEDs, white and blue [16], but gave no experimental demonstration of laser effect.

Furthermore, it is worth noting that many results were reported on LED pumped Nd:YAG lasers but nothing with $\mathrm{Nd}: \mathrm{YVO}_{4}$ crystals (probably partly because a $\mathrm{YVO}_{4}$ matrix appeared after the vanishing of LED pumping). Compared to Nd:YAG, the product of the emission cross section by the lifetime is still two times higher and can, therefore, produce a much higher optical gain. Consequently, $\mathrm{Nd}: \mathrm{YVO}_{4}$ lasers combined with new intensities of today's LEDs should result in promising performance. In this Letter, we investigate both experimentally and theoretically an $\mathrm{Nd}: \mathrm{YVO}_{4}$ laser transversely pumped by pulsed near IR-LED. 


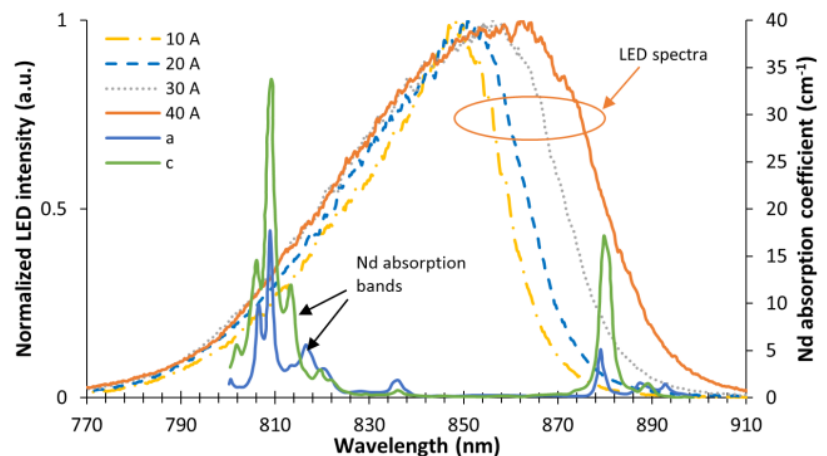

Fig. 1. Spectral deformation with respect to the injected current and $\mathrm{Nd}: \mathrm{YVO}_{4}$ absorption bands for 1 at. \% doping concentration [23].

As pump source, we used near-IR LEDs centered at 850 $\mathrm{nm}$ from Light Avenue. A dice of $1 \mathrm{~mm}$ by $1 \mathrm{~mm}$ emits an intensity of $25 \mathrm{~W} / \mathrm{cm}^{2}$ at a continuous drive current of $1 \mathrm{~A}$. Basic calculations based on small signal gain (see below for theory) show that this value is currently too low to reach the laser threshold. Therefore, we operated the LEDs in pulsed regime. The current driven by PCO-6131 (Directed Energy, Inc) injected into the LEDs had a square shape, with a pulse duration of $100 \mu \mathrm{s}$ (in accordance to the $\mathrm{Nd}: \mathrm{YVO}_{4}$ lifetime). By increasing the current, each chip emits a peak output intensity of 200 $\mathrm{W} / \mathrm{cm}^{2}$ at $40 \mathrm{~A}$, eight times higher than in the $\mathrm{CW}$ operation. Beyond this current, the one mil $(\approx 25 \mu \mathrm{m})$ gold wires between the dices and the electrical track evaporated. In pulsed operation, we measured the emission spectrum (Fig. 1) and found that the spectral width increases from $35 \mathrm{~nm}$ to $60 \mathrm{~nm}$ between 10 and $40 \mathrm{~A}$. This effect can be explained by the temperature increase of the LEDs at high current values.

An LED array consists in a line of $181 \mathrm{~mm} \times 1 \mathrm{~mm}$ chips. We used two arrays of LED, on two opposite sides of the laser crystal. Each chip is separated by $0.3 \mathrm{~mm}$ from each other (illustrated in the inset of the Fig. 2). Each LED array is placed on a water cooled copper mount to reduce the LED heating. We studied the energy contained in a $100 \mu$ s pulse at $40 \mathrm{~A}$ as a function of the repetition rate of the LEDs. Figure 2 illustrates this measurement for all the LEDs. We observed that, at this current, the energy was stable (around $7.4 \mathrm{~mJ}$ ) for frequencies below $250 \mathrm{~Hz}$ and began to drop slightly for higher frequencies to finally stop to emit above $400 \mathrm{~Hz}$. At

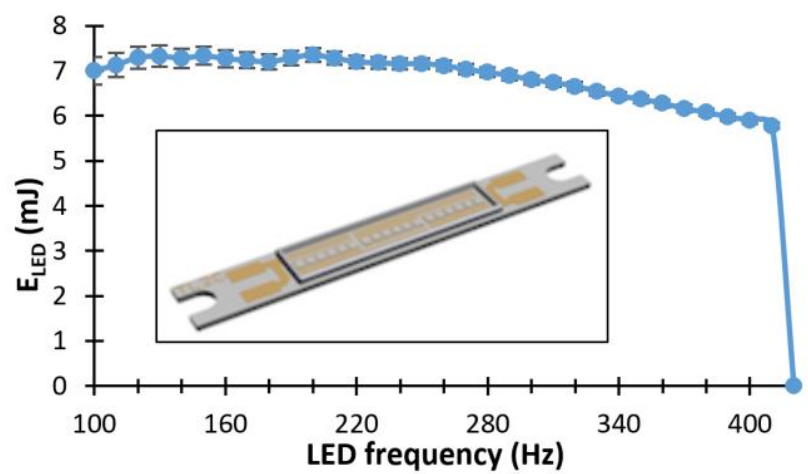

Fig. 2. Evolution of the pump energy emitted by the two LED arrays as a function of the repetition rate. Inset: illustration of the LED array. this frequency and this current, the gold wires melt. This is why all our measurements have been done far below this value (namely $250 \mathrm{~Hz}$ ).

As the emission diagram of LED is lambertian, it is very difficult to collect all the emitted flux with optics. It is nearly impossible to focus the LED beam with a higher intensity (in $\mathrm{W} / \mathrm{cm}^{2}$ ) than the intensity at the surface of the dice itself. Therefore, we chose to design a pumping configuration without optics, the LED beam being close coupled in the laser crystal. To increase the number of LED, we use a transverse pumping configuration to distribute the LED all along the crystal faces in a setup described on Fig. 3.

The laser crystal is an a-cut $20 \mathrm{~mm}$ long $\mathrm{Nd}: \mathrm{YVO}_{4}$ crystal with a doping concentration of 1 at.\% and a $2 \mathrm{~mm}$ x $2 \mathrm{~mm}$ square section. The orientation of the crystal has been picked to maximize the absorption, that is to say that the pumping is done along the (a,c) axes. The doping concentration has been chosen to be as high as possible while avoiding concentration quenching [17,18]. Two transverse faces are polished for the pumping. However, the transverse faces are not AR coated. The two other faces are used to cool the crystal. As the large emission cross section of $\mathrm{Nd}: \mathrm{YVO}_{4}$ is very sensitive to temperature changes $[19,20]$, the crystal is held by two water cooled copper mounts to extract the heat induced by the pumping. Both crystal laser facets are AR coated with a reflectivity below $0.1 \%$ at $1064 \mathrm{~nm}$. We designed a planoconcave cavity with an HR coated end mirror having a radius of curvature of $500 \mathrm{~mm}$ and a plane output coupler. The cavity length can be adjusted from 200 to $500 \mathrm{~mm}$ to optimize the output energy.

First, we measured the performance of our system for different transmissions of the output coupler (Fig. 4). Our best results have been obtained with a $1 \%$ transmission output coupler. In this configuration, we found a pump energy threshold of $1.84 \mathrm{~mJ}$ and obtained nearly $40 \mu \mathrm{J}$ of laser energy for an input energy of $7.4 \mathrm{~mJ}$ at a repetition rate of $250 \mathrm{~Hz}$. This corresponds to an optical efficiency between the laser energy and the total energy emitted by the LEDs of $0.5 \%$. Additionally, we studied the spatial profile of our laser by imaging the beam waist with a $75 \mathrm{~mm}$ focal length lens in a $2 \mathrm{f}-2 \mathrm{f}$ configuration. We measured an $\mathrm{M}^{2}$ factor of 19 , corresponding to the large pump volume related to the transverse pumping configuration. We have also monitored the laser pulse shape (Fig. 4). For a pump pulse duration of $100 \mu \mathrm{s}$, the laser pulse is about $65 \mu$ s long at $40 \mathrm{~A}$. We clearly observe the transient buildup of the laser with the spiking behavior at the beginning of the pulse. Then, the laser converges to a continuous value in the second half of the pulse, corresponding to the quasi-continuous regime.

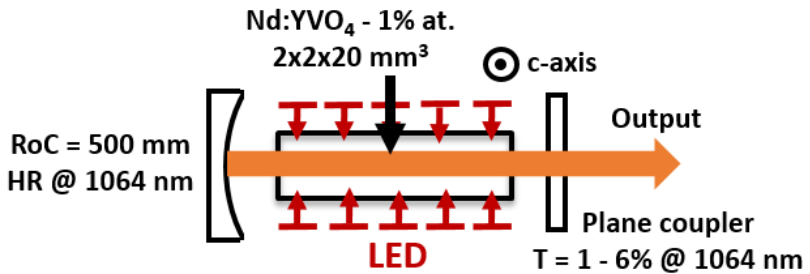

Fig. 3. Experimental setup. 


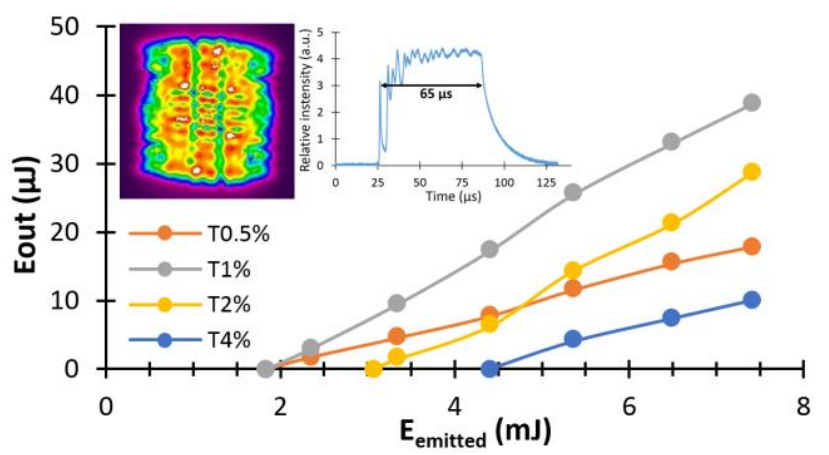

Fig. 4. Evolution of the output energy as a function of the input pump energy. Inset: spatial and temporal profiles of the laser beam at a pump energy of $7.4 \mathrm{~mJ}$.

Subsequently, to explore the maximal gain available, we progressively increased the transmission of the output coupler and noted the corresponding pump energies required to reach the laser threshold. Figure 5 illustrates the small-signal gain $\mathrm{G}_{0}$ as a function of the pump energy at the laser threshold. We obtained a single pass small signal gain $\mathrm{G}_{0}$ up to 1.042 . The solid and dash curves represent the theoretical evolutions from our simulations presented in the following paragraph.

To calculate the small signal gain available with this LED pumped system, we used the gain coefficient $\left(\mathrm{cm}^{-1}\right)$ described by Eq. (1), taking into account that LEDs are non-monochromatic sources:

$$
g=\frac{n_{t} \sigma_{e l} \tau}{h c} \int_{\lambda_{p 1}}^{\lambda_{p 2}} \sigma_{a p}\left(\lambda_{p}\right) \lambda_{p} \frac{d I_{p}}{d \lambda_{p}} d \lambda_{p}
$$

where $n_{t}$ is the total population density of $\mathrm{Nd}^{3+}$ ions in the $\mathrm{YVO}_{4}, \sigma_{a p}$ is the absorption cross section at the pump wavelength, $\sigma_{e l}$ is the emission cross section at the laser wavelength, $I_{p}$ is the pump intensity (in W/ $\mathrm{cm}^{2}$ ), $\lambda_{p}$ is the pump wavelength, $h$ is the Planck constant, $c$ is the speed of light in vacuum, and $\tau$ is the lifetime of the laser transition. Finally, as the pump pulse duration $(100 \mu \mathrm{s})$ is the same order as the lifetime of $\mathrm{Nd}$ in $\mathrm{YVO}_{4}(90 \mu \mathrm{s})$, the real gain is not the steady-state gain. To take the transient buildup into account, we defined a gain coefficient $g^{\prime}$ at the end of the pump pulse to be

$$
g^{\prime}=g\left(1-e^{-\frac{\Delta t}{\tau}}\right)
$$

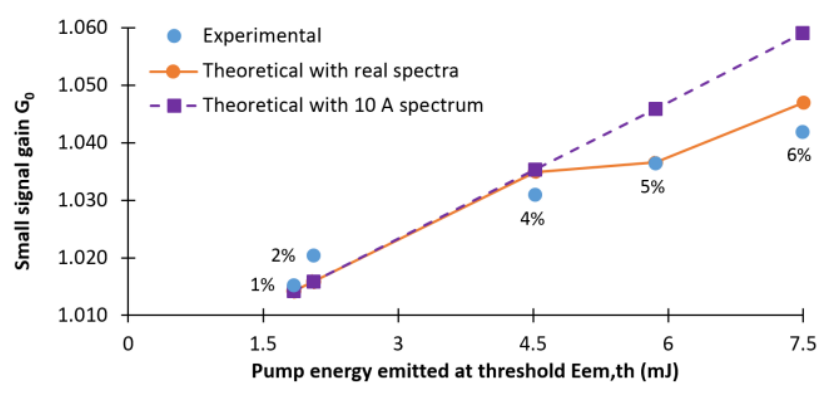

Fig. 5. Theoretical and experimental small-signal gain as a function of the pump energy $\mathrm{E}_{\text {em,th }}$ needed to reach the laser threshold for, different output couplers. where $\Delta t$ is the pump pulse duration. Considering $\mathrm{L}$ as the crystal length, we can now calculate the small-signal gain $\mathrm{G}_{0}$ (in single pass):

$$
G_{0}=e^{g^{\prime} L}
$$

Crystal losses $\alpha$ were assumed to be negligible. Thus, we deduce from the relations (1) and (3) that we need to know $I_{p}$ at any point in the crystal to have access to $\mathrm{G}_{0}$. Thereby, we have used a ray tracing software (LightTools) which allowed us to simulate our system numerically [21]. After entering all the parameters, we have access to the pump intensity at any points in the crystal and are able to determine the repartition of laser gain inside the crystal.

These simulations allow us to highlight the effects of the LED's spectrum on the gain. Indeed, on the Fig. 5, the dashed line represents the theoretical evolution of the small signal gain when we consider a $35 \mathrm{~nm}$ wide spectrum (corresponding to $10 \mathrm{~A}$ driving current) regardless of the injected current, while the solid line is the result when we take into account the broadening of the spectrum versus the driving current. Thus, we deduce from our simulations that the LED spectral broadening is a critical parameter, strongly limiting the small signal gain and hence the laser performance.

Since the simulation was validated by experimental data in Fig. 5, it became a tool to investigate the influence of other key parameters coming from the pump geometry, namely the distance between the LED and the crystal (parameter $X$ described in Fig. 6) and the misalignment between the two LED arrays, called $Y$.

First, Fig. 7 shows that the small signal gain is very sensitive to the distance $X$ between the LED arrays and the crystal; since the incident pump intensity $\left(\mathrm{W} / \mathrm{cm}^{2}\right)$ depends on the square of the distance to the crystal, a small increase of the LED-crystal distance can lead to an important decrease of the gain inside the crystal. In our setup, the working distance cannot be less than $700 \mu \mathrm{m}$ due to the protective glass and the bond line (see Fig. 6); this reduces the gain by a factor of 0.5 compared to the maximum value (reached when the LEDs and the crystal are very close).

Gain evolution with a misalignment $Y$ between the LEDs is less sensitive. However, one has to control this parameter carefully since a misalignment of $1 \mathrm{~mm}$

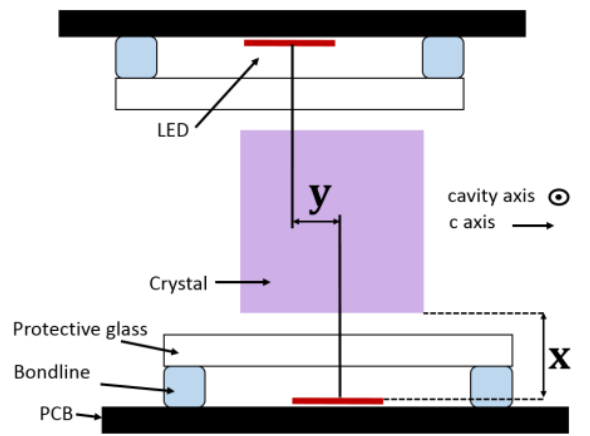

Fig. 6. Transversal view of the pumping scheme with the crystal at the center and the LED arrays on two opposite sides. X \& Y are two key spatial parameters. 


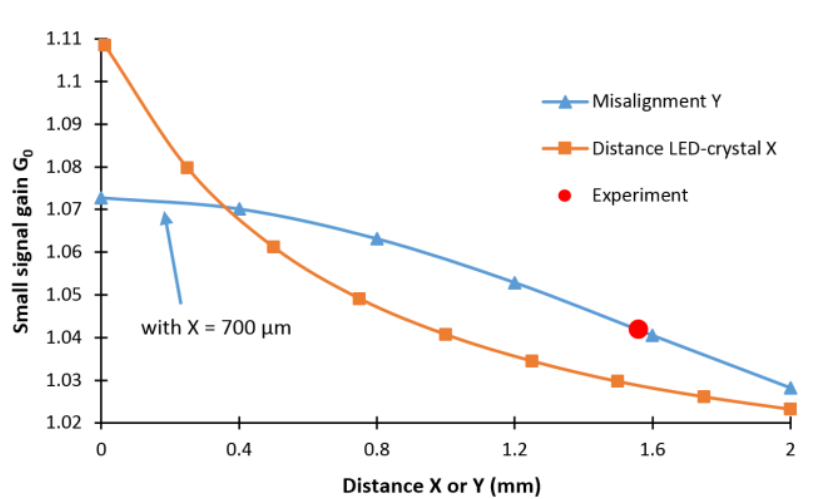

Fig. 7. Evolution of the theoretical small signal gain $\mathrm{G}_{0}$ as a function of the misalignment between the two LEDs (Y) and the distance between LEDs and the crystal (X). This calculations are used to estimate the misalignment $\mathrm{Y}$ in our experiment.

(namely half of the crystal size) between each LED array and the crystal can reduce the gain by $20 \%$. This curve has been done with $X$ set to $700 \mu \mathrm{m}$ (the real distance between the crystal and LEDs), allowing us to place our experimental point on this curve. This gives an estimation of the LED misalignment in our setup: close to $1.5 \mathrm{~mm}$. This high value can be explained by the setup itself having no controlled adjustment to move the LED arrays precisely.

Our simulation can also estimate the absorbed energy. Indeed, only $78 \%$ of the LED energy reaches the crystal because of the distance between the latter and the LEDs. Then, another $10 \%$ are lost because of the non-AR coated pumped crystal faces. Moreover, as anticipated in Fig. 1, the absorption is relatively weak. It is partially compensated by the optical path inside the crystal by nonperpendicular rays or rays being trapped by total internal reflection. Taking in account all the rays coming from the LEDs, we estimated using LightTools that $30 \%$ of the pump energy is absorbed. Hence, from the $7.4 \mathrm{~mJ}$ emitted by the LED, only $1.5 \mathrm{~mJ}$ is really absorbed. This leads to an optical efficiency of $2.6 \%$ related to the absorbed energy.

To increase the output energy and efficiency, there are several possible axes of improvement. As presented in Fig. 7, a chip on board LED with shorter working distance would allow a better pump coupling into the crystal. Also, LEDs with same intensity but with a spectrum centered near the $808 \mathrm{~nm}$ absorption band instead of $850 \mathrm{~nm}$ could widely improve the results.

Energy scaling may also be considered by using double stack LEDs emitting 1.6 times more than single LEDs for the same emitting area [22]. In addition, it could be possible to use 2 lines of 18 LEDs to have a pump area as large as the transverse dimension of the crystal. It may be also possible to use dices with bigger gold wires, which would allow to operate the LED at higher currents and higher repetition rates.

In conclusion, we have demonstrated that it is possible to create a laser effect, at a room temperature, from a $\mathrm{Nd}: \mathrm{YVO}_{4}$ laser transversely pumped by LED near $850 \mathrm{~nm}$. To the best of our knowledge, this gain medium was never LED pumped before this work and represents the first LED pumped Nd:YVO 4 laser. We obtained $40 \mu \mathrm{J}$ at a frequency of $250 \mathrm{~Hz}$. The corresponding optical efficiency is about $0.5 \%$ (2.6\% related to the absorbed energy). LED lighting is a very active and growing market, constantly improving the LED performance. This first demonstration with $\mathrm{Nd}: \mathrm{YVO}_{4}$ shows that it will be worth to consider LED pumping of bulk crystals in the future, particularly in the visible range where LED are highly optimized.

The authors acknowledge the Agence Nationale de la Recherche (EDELVEIS project), the Labex PALM and the Conseil Régional d'Ile de France for the funding of this research.

\section{References}

1. T. Maiman, Nature, 187, 494 (1960).

2. S. A. Ochs and J. I. Pankove, in Proceedings of the IEEE, p. 713 (1964).

3. R. B. Allen and S. J. Scalise, Appl. Phys. Lett., 14, 188 (1969).

4. F. W. Ostermayer, Appl. Phys. Lett., 18, 93 (1971).

5. G. I. Farmer and Y. C. Kiang, J. Appl. Phys., 45, 1356 (1974).

6. M. Saruwatari, T. Kimura, T. Yamada, and J. Nakano, Appl. Phys. Lett., 27, 682 (1975).

7. J. Stone, C. a. Burrus, a. G. Dentai, and B. I. Miller, Appl. Phys. Lett., 29, 37 (1976).

8. V. Bilak and I. Goldobin, Sov. J. Quantum Electron., 11, 1471 (1981)

9. A. R. Reinberg, L. A. Riseberg, R. M. Brownn R. W. Wacker, W. C. Holton, Appl. Phys. Lett., 19, 11 (1971).

10. Led. Magazine, "Lab record: red LED breaks through the $200 \mathrm{Im} /$ W barrier" $(2011)$.

11. Y. Yang, G. a. Turnbull, and I. D. W. Samuel, Appl. Phys. Lett., 92, 163306 (2008).

12. J. Herrnsdorf, Y. Wang, J. J. D. McKendry, Z. Gong, D. Massoubre, B. Guilhabert, G. Tsiminis, G. a. Turnbull, I. D. W. Samuel, N. Laurand, E. Gu, and M. D. Dawson, Laser Photon. Rev., 7, 1065 (2013).

13. L. Htein, W. Fan, P. R. Watekar, and W.-T. Han, Opt. Lett., 37, 4853 (2012).

14. L. Htein, W. Fan, P. Wateker, and W. Han, IEEE Photonics Technol. Lett., 25, 1081 (2013).

15. X. Liu, G. Zhao, Y. Zhang, and D. G. Deppe, Appl. Phys. Lett., 102, 081116 (2013).

16. K. Lee, S. Bae, J. S. Gwag, J. H. Kwon, and J. Yi, J. Korean Phys. Soc., 59, 3239 (2011).

17. Z. Huang, Y. Huang, Y. Chen, and Z. Luo, JOSA B, 22, 2564 (2005).

18. A. Sennaroglu, Opt. quantum Electron., 32, 1307 (2000).

19. X. Délen, F. Balembois, and P. Georges, J. Opt. Soc. Am. B, 28, 972 (2011).

20. Y. Sato and T. Taira, Opt. Mater. Express, 2, 1076 (2012).

21. S. O. Solutions, "LightTools."

22. OSRAM Opto Semiconductors, "LED SFH 4715S."

23. L. Mcdonagh, R. Wallenstein, R. Knappe, and A. Nebel, Opt. Lett., 31, 3297 (2006). 